\title{
O papel da ouvidoria pública: uma análise a partir das dimensões funcional, gerencial e cidadã
}

\author{
Aline Regina Santos \\ Universidade do Estado de Santa Catarina (UDESC)
}

Jane lara Pereira da Costa

Universidade do Estado de Santa Catarina (UDESC)

Fabrício Burger

sem vínculo com IES

Rafael Tezza

Universidade do Estado de Santa Catariana (UDESC)

As ouvidorias públicas visam promover a melhoria da qualidade do serviço público a partir da livre manifestação do cidadão. Assim, assumem distintos papéis que englobam aspectos funcionais, como receber e analisar as manifestações; aspectos gerenciais, que envolvem a transformação das manifestações em possibilidades de melhoria no serviço público; e aspectos de cidadania, ao possibilitar que o cidadão exerça seu direito de participar na administração pública, fomentando o controle social. Considerando o exposto, o estudo objetiva analisar os papéis atribuídos à ouvidoria pública, observando como são aplicados e percebidos pelos ouvidores. Para tanto, uma pesquisa survey foi realizada com 156 ouvidores públicos vinculados ao Poder Executivo do Estado de Santa Catarina, permitindo cotejar os dados coletados às dimensões previamente identificadas. Mediante análise fatorial exploratória, foi possível identificar duas dimensões predominantes - e não três, como previsto anteriormente. Além disso, os resultados indicam a divulgação à comunidade, seja das demandas ou da ouvidoria em si, como atividade menos recorrente entre as realizadas pelos ouvidores, situação que estimula o debate sobre a natureza da própria ouvidoria pública.

Palavras-chave: ouvidoria pública, participação cidadã, serviço público

[Artigo recebido em 27 de janeiro de 2018. Aprovado em 25 de outubro de 2019.] 


\section{El papel de la defensoría del pueblo: un análisis desde las dimensiones funcional, gerencial} y ciudadana

Las defensorías del pueblo tienen como objetivo promover la mejora de la calidad del servicio público de la manifestación libre del ciudadano. Así, asumen diferentes roles que abarcan aspectos funcionales, tales como la recepción y el análisis de las manifestaciones; Aspectos gerenciales, que impliquen la transformación de las manifestaciones en posibilidades de mejora en el servicio público; y los aspectos de la ciudadanía, al permitir al ciudadano ejercer su derecho a participar en la administración pública, fomentando el control social. Teniendo en cuenta lo anterior, el estudio pretende analizar los roles atribuidos a la Defensoría del Pueblo, observando cómo son aplicados y percibidos por los defensores. Para tanto, una encuesta fue hecha con 156 oyentes vinculados al Poder Ejecutivo del Estado de Santa Catarina, permitiendo la recopilación de los datos recogidos a las dimensiones previamente identificadas. A través del análisis factorial exploratorio fue posible identificar dos dimensiones predominantes - no tres, como se predijo previamente. Además, los resultados indican la divulgación a la comunidad, ya sea de las reivindicaciones o de la propia Defensoría, como actividad menos recurrente entre los que llevan a cabo los oyentes, situación que alienta el debate sobre la naturaleza de la propia Defensoría del Pueblo.

Palabras clave: defensoría del pueblo, participación ciudadana, servicio público

The public's ombudsman role: an analysis from functional, managerial, and citizen dimensions

Public ombudsman office aims to promote the improvement of public service quality from the free manifestation of the citizen. Thus, it assumes different roles that encompass functional aspects, such as receiving and analyzing citizen's claims; managerial aspects, which involves turning complains into possibilities for improvement in the public service; and aspects of citizenship, by enabling citizens to exercise their right to participate in public administration and to promote social control. Considering this context, the present study aims to analyze the roles of the Public Ombudsman Office, observing how they are applied and perceived by the ombudsmen. Therefore, a survey was held to 156 ombudsmen linked to the Executive Branch of the Santa Catarina state, allowing compare the data to the previously identified dimensions. Through exploratory factorial analysis, it was possible to identify two predominant dimensions - not three, as previously predicted. Besides, results indicate the disclosure to the community as a less recurrent activity among those carried out by the listeners. This situation encourages the debate on the nature of the Public Ombudsman itself.

Keywords: public ombudsman office, citizen participation, public service 


\section{Introdução}

As ouvidorias públicas estão presentes no Brasil desde o período colonial. Entretanto, é somente com a redemocratização e o fim da ditadura militar que encontram espaço para crescimento (MORAES et al., 2010; OUVIDORIA GERAL DA UNIÃo, 2012). O debate sobre a construção de um Estado Democrático de Direito e de uma democracia participativa culminam na promulgação da Constituição Federal de 1988 (CF), importante marco na história do país. Se antes não era permitido ao cidadão questionar e se expressar livremente, com a CF a participação popular na administração pública torna-se um direito constitucional, expresso em seu artigo 37.

São diversas as formas de participação popular, compreendendo desde o voto até a formulação de políticas públicas. Para Duarte (2007), a participação popular é fator primordial à construção da cidadania, uma vez que é dada voz ao cidadão, tornando-o um membro legítimo e igual perante os demais, dentro de uma determinada sociedade. Naturalmente, a participação cidadã transcende a reclamação por causa de serviços insatisfatórios nas ouvidorias e nos diversos ambientes de atendimento ao cidadão, mas não a exclui. Tal abordagem é perceptível na própria definição das ouvidorias públicas, publicada em cartilha desenvolvida pela Ouvidoria Geral da União.

A ouvidoria pública deve ser compreendida como uma instituição que auxilia o cidadão em suas relações com o Estado. Deve atuar no processo de interlocução entre o cidadão e a administração pública, de modo que as manifestações decorrentes do exercício da cidadania provoquem contínua melhoria dos serviços públicos prestados (OUVIDORIA GERAL DA UNIÃo, 2012, p.8).

Corroborando o exposto, o documento afirma ser o papel da ouvidoria pública "não o de procurar e apontar defeito na ação da instituição, mas funcionar como um controle social da qualidade do serviço público, auxiliando na busca de solução para os problemas existentes na instituição" (OUVIDORIA GERAL DA UNIÃo, 2012, p.17).

Apesar da relevância atribuída à ouvidoria e da possibilidade de relacioná-la a importantes temáticas da administração pública, como participação cidadã e controle social, a literatura sobre o tema ainda é escassa. Vianna (2012) pontua a existência de menos de 30 livros e poucas publicações acadêmicas sobre o tema. Em revisão sistemática compreendendo o período de 2002 a 2013, Santos et al. (2015) identificaram 23 artigos científicos publicados em periódicos e nos eventos da Associação Nacional de Pós-Graduação e Pesquisa em Administração (Anpad) na área de Administração/Gestão Pública. Nestes, são recorrentes assuntos como o histórico das ouvidorias, sua estrutura, processo de implementação e aplicação em contextos específicos, como as ouvidorias municipais ou da área da saúde, por exemplo. 
Diante do contexto apresentado, o intuito da presente pesquisa foi aprofundar a análise sobre o papel das ouvidorias, tendo como ponto de partida as atribuições indicadas pela Ouvidoria Geral da União e literatura disponível na área. Como resultado, foram identificadas três dimensões relacionadas às ouvidorias públicas: a funcional, a gerencial e a cidadã. Buscou-se, a partir de então, verificar se as atividades desempenhadas pelos ouvidores e suas equipes são condizentes com as dimensões mapeadas neste estudo. Os resultados obtidos são apresentados ao final deste artigo, sendo precedidos por explanação teórica, aspectos metodológicos e apresentação dos resultados.

\section{Aspectos históricos da ouvidoria pública}

A história da ouvidoria pública se inicia na Suécia. Oficialmente estabelecido na constituição de 1809, após o período de dominação russa, o ouvidor (justitieombudsmannen) tinha como função fiscalizar a observância às leis e estatutos. Além de investigar os atos irregulares cometidos por outros agentes públicos, poderia também processá-los, aproximando-se da figura de um "procurador de justiça". Nos anos seguintes, esta função se modificou dando espaço ao defensor dos cidadãos. (HOWARD, 2010; REIF, 2004)

A expansão para outros países escandinavos levou aproximadamente um século, começando pela Finlândia, seguido por Normandia e Dinamarca. Conforme explica Howard (2010), os ouvidores realizavam as investigações a partir de denúncias formais dos cidadãos ou mesmo pela constatação de um problema. Eles poderiam solicitar esclarecimentos dos envolvidos e registrar o ocorrido em relatórios oficiais.

A segunda fase de expansão ocorreu nas décadas de 1960 e 1970, começando pela Alemanha e Nova Zelândia, com rápida adesão por outros países europeus e da América do Norte. Trata-se de um período em que se evidencia o esgotamento do modelo burocrático weberiano e a introdução dos modelos gerenciais de administração pública. Neste, a lógica consiste em tornar a gestão pública mais eficiente mediante uso de práticas e ferramentas gerenciais existentes no setor privado (ABRUCIO, 1997). O trecho a seguir ilustra como a ouvidoria foi introduzida nos EUA, no início de seu processo de implantação, em 1961.

Quando um burocrata te irrita, ou demora muito, ou fica preso ao excesso de regras, ou nega o que você precisa, é possível - de maneira fácil e rápida - encontrar um alívio (...), basta escrever ao Ouvidor. Se o burocrata estiver errado, o Ouvidor pode, publicamente, reprimi-lo. (...) Isto é o que acontece em lugares como Etiópia e Escandinávia (DAvIS apud HowARD, 2010, p.6, tradução nossa). 
Em meados de 2003, aproximadamente 110 países já apresentavam estruturas de ouvidoria, embora com características distintas. Na Argentina, Áustria, Bélgica e Espanha, por exemplo, há uma "ouvidoria nacional" de atuação mais ampla, além das ouvidorias nas esferas federal, estadual e municipal. Já no Canadá, Índia, Itália e EUA, há somente a atuação nas três esferas. Outra distinção é feita em relação ao modelo adotado, se clássico ou híbrido (REIF, 2004).

No modelo clássico, o ouvidor é indicado pelo governo, sendo profissional de elevada competência. Atua desvinculado dos poderes, de forma autônoma, sendo responsável por receber as reclamações da população contra agentes públicos, como servidores, políticos, oficiais, etc., que agem em benefício próprio. O ouvidor tem o poder de investigar, recomendar ação corretiva e reportar as questões levantadas a órgãos superiores. Segundo Reif (2003, p. 4), ao ouvidor é dado elevado poder de investigação, "estes poderes incluem obrigar a produção de documentos e o comparecimento e depoimento de testemunhas. Embora estes poderes sejam importantes para atuação do ouvidor, na prática não devem ser usados com frequência".

A autora afirma que, após uma investigação imparcial, o ouvidor determina se houve ou não conduta imprópria do agente público, conduta adequada ou não. Caso uma conduta equivocada seja descoberta, o ouvidor tem poder para fazer recomendações de mudanças, visando solucionar o problema. De acordo com Reif (2004), muitos ouvidores têm poder, inclusive, de sugerir alterações nas leis. Além disso o ouvidor tem o dever de elaborar relatórios anuais sobre as atividades da ouvidoria e relatórios especiais, se necessário, baseados em investigações específicas. Pontua-se que, no modelo clássico, o ouvidor não pode investigar situações que envolvam organizações do setor privado.

No modelo híbrido, por sua vez, há possibilidade de atuação entre os setores público e privado. Esse tipo de ouvidoria atua num espectro entre o modelo clássico de ouvidoria e as comissões de direitos humanos e de combate à corrupção. Desponta no final da década de 1970 em muitos países que sofreram abusos na área. Os profissionais que atuam nos processos investigativos são figuras públicas amparadas na constituição (Provedor de Justiça, Portugal, 1975; Defensor do Povo, Espanha, 1978; Promotor de Justiça, Brasil, 1988).

Ouvidorias de modelo híbrido são criadas quando é dada a possibilidade às ouvidorias de combater a corrupção. Enquanto há diferentes formatos de accountability horizontal estabelecidos para combater a corrupção, incluindo cortes e comissões de combate à corrupção, alguns países que não criaram uma instituição específica com tal propósito dotaram às ouvidorias um papel de anticorrupção (REIF, 2004, p.10, tradução nossa) 
Reif (2004) afirma não haver uma predominância de um modelo sobre o outro, uma vez que, dos 110 países que apresentam ouvidorias, cerca de 50\% adota modelo híbrido, e outros $50 \%$, o clássico.

\section{A ouvidoria pública no Brasil}

A trajetória das ouvidorias públicas no Brasil inicia-se no Brasil Colônia, com a figura do "ouvidor". Entretanto, diferentemente de receber e analisar reclamações da população, o ouvidor tinha como papel reportar ao rei de Portugal o que ocorria na colônia. É somente no Brasil Império que as atribuições do ouvidor se aproximam das atuais, ainda que de forma incipiente. Durante a República, em específico, no período da ditadura militar (1964-1985), as funções do ouvidor foram paralisadas (LACERDA, 2007; OUVIDORIA GERAL DA UNIÃO, 2012)

A década de 1980 foi marcada pelo enfraquecimento do militarismo e pelo processo de redemocratização, culminando na promulgação da Constituição Federal (CF) de 1988. Tendo os direitos fundamentais como princípio do Estado brasileiro, a CF estimula o controle social e a participação cidadã, ainda que não institucionalize as ouvidorias públicas. $O$ incentivo ao controle social, combinado à expansão das ouvidorias em escala global, resultou no florescimento das ouvidorias públicas no Brasil, tal como existe na atualidade.

A primeira ouvidoria pública do Brasil foi criada em 1986, em Curitiba, Paraná, atuando em instância municipal. Alguns anos depois, em 1992, é criada a OuvidoriaGeral da República, vinculada ao Ministério da Justiça. No entanto, foi no final da década de 1990, a partir de 1998, que o processo de institucionalização e desenvolvimento das ouvidorias começou a se solidificar.

Em 1998, o artigo 37o da CF é alterado mediante a inclusão da alínea I, que adiciona às formas de participação "as reclamações relativas à prestação dos serviços públicos em geral, asseguradas a manutenção de serviços de atendimento ao usuário e a avaliação periódica, externa e interna, da qualidade dos serviços". Esta modificação na CF pode ser observada como uma alusão à atividade das ouvidorias, ratificando a relevância desta à administração pública (OUVIDORIA GERAL DA UNIÃO, 2012).

No ano seguinte, em 1999, o Estado de São Paulo criou um sistema de ouvidorias públicas. Romero e Sant'Anna (2014) enfatizam que as iniciativas da Prefeitura de Curitiba e do Estado de São Paulo partem do Poder Executivo, com a finalidade de garantir ao cidadão a melhoria da qualidade dos serviços públicos. Segundo os autores, 
além de garantir a possibilidade de reclamar da qualidade dos serviços públicos, essa rede de ouvidorias públicas veio facilitar o acesso à informação pública. Assim, a sociedade passou a ter um canal aberto de acesso à informação (ROMERo E SANT'ANNA, 2014, p.190).

Importante destacar que, a partir de meados da década de 1990, intensifica-se no Brasil o movimento de reforma administrativa. Neste, o modelo gerencialista ganha amplitude na administração pública brasileira, com a finalidade de melhorar o desempenho do Estado mediante a oferta de serviços públicos com maior qualidade e eficiência, bem como de ampliar as bases da democratização (Pó; ABRUCIO, 2006; LIMA, 2007).

Outro ponto relevante no histórico do país trata da promulgação da Lei $\mathrm{n}$ o 12.527/2011, conhecida como Lei de Acesso à Informação (LAI). A lei determina que os órgãos da administração pública, direta ou indireta, proporcionem um amplo acesso à informação e sua divulgação, de forma que a gestão da informação pública ocorra com transparência (BRASIL, 2011). Romero e Sant'Anna (2014) explicam que a LAI provocou uma ampla mudança em curto espaço de tempo, segundo os autores.

A administração pública passou a ser obrigada a colocar à disposição do cidadão uma gama de informações até então mantidas encobertas pela burocracia estatal. Além de agora oferecerem ao público os chamados portais da transparência, os órgãos também passaram a atender prontamente às mais diversas solicitações de informações (ROMERO; SANT'ANNA, 2014, p.190).

Em muitos órgãos públicos, tais solicitações passaram a ser atendidas pelas ouvidorias, embora a orientação da Controladoria-Geral da União seja de que as demandas da LAI sejam atendidas por setor específico, o Serviço de Informação ao Cidadão (SIC) (CONTROLAdORIA-GERAL DA UNIÃO, 2015).

Tal cenário colabora para o crescimento das ouvidorias públicas no Brasil, haja vista a expressão da LAI, somada à percepção de que a melhoria na qualidade do serviço público pode ocorrer a partir da manifestação do cidadão-usuário do serviço. O crescimento no número de ouvidorias públicas na última década é expresso na Figura 1. 


\section{Figura 1 - Ouvidorias do Poder Executivo federal 2002 - 2014}

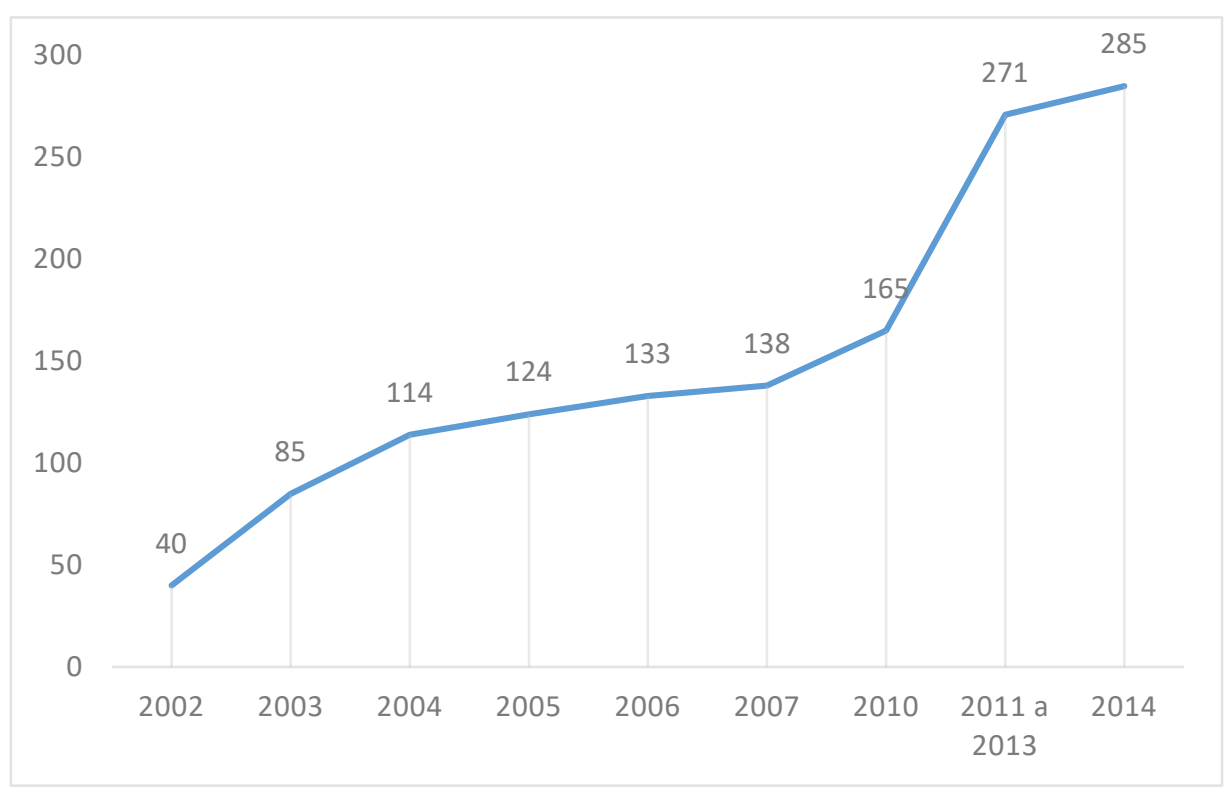

Fonte: Ipea e CGU (2014, p.5).

Pontua-se que os dados representam somente ouvidorias públicas federais, portanto, o número de ouvidorias públicas no Brasil é ainda maior. O Relatório Coleta 2014, desenvolvido pelo Ipea e CGU (2016) indica que, das 176 ouvidorias que participaram do levantamento de dados, $94 \%$ são pertencentes à esfera federal, enquanto $6 \%$ atuam no âmbito estadual. As 285 ouvidorias indicadas na figura estão cadastradas na Ouvidoria Geral da União.

Se consideradas as ouvidorias públicas não registradas na Ouvidoria Geral da União, a dimensão dessa atividade no Brasil, especialmente nas instâncias estaduais e municipais, pode se ampliar substancialmente. Somente no Estado de Santa Catarina, 261 ouvidorias públicas (estaduais) são vinculadas à Ouvidoria Geral do Estado, segundo dados coletados nesta pesquisa.

\section{As dimensões da ouvidoria pública}

A cartilha de Orientações para implantação de uma unidade de ouvidoria (OUVIDORIA GERAL DA UNIÃo, 2012, p.12) define o propósito da ouvidoria como sendo o de "buscar soluções para as demandas dos cidadãos; oferecer informações gerenciais e sugestões ao órgão em que atua, visando ao aprimoramento da prestação do serviço, além de contribuir para a formulação de políticas públicas". Ainda, indica as atividades necessárias para que o propósito seja alcançado, expresso nas "competências da ouvidoria e do ouvidor", quais sejam: 
receber, examinar e encaminhar reclamações, sugestões, elogios, informações, denúncias e representações;

responder ao interessado acerca das manifestações apresentadas;

acompanhar as providências adotadas até a obtenção da solução que o caso requer;

sugerir a adoção de medidas visando o aperfeiçoamento na prestação do serviço público;

organizar e interpretar as informações colhidas das áreas técnicas sobre assuntos de sua competência;

estimular as ações de democracia participativa; e

apoiar as ações de transparência, tanto na modalidade ativa quanto na passiva (OUVIDORIA GERAL DA UNIÃO, 2012, p. 20).

É possível perceber competências operacionais, vinculadas à rotina de trabalho dos ouvidores e sua equipe, tais como "receber, examinar e encaminhar as manifestações", bem como "responder ao interessado acerca das manifestações apresentadas" e "acompanhar as providências adotadas". Outras apresentam aderência às atividades de gestão, pois se voltam à melhoria da prestação do serviço. Tais funções são observadas nas competências de "sugerir a adoção de medidas, visando ao aperfeiçoamento na prestação do serviço público" e de "organizar e interpretar as informações colhidas das áreas técnicas sobre assuntos de sua competência". E, por fim, são observadas competências no tocante ao estímulo da cidadania, observadas no "estímulo às ações de democracia participativa" e no "apoio às ações de transparência". Essa análise revela alguns dos papéis atribuídos às ouvidorias, categorizados neste trabalho em três dimensões: cidadã, gerencial e funcional.

Em uma abordagem voltada ao setor privado, Kalil (2013) categoriza as ouvidorias em duas perspectivas: a reativa e a preventiva. A atuação reativa envolve o atendimento das demandas individuais, registradas na ouvidoria, assim, compreende as atividades que têm como ponto de partida a manifestação do reclamante.

Ao registrar a reclamação a ouvidoria deve encaminhá-la de imediato aos gestores responsáveis, que darão solução ou sugestão de solução à causa. A ouvidoria não deve fornecer resposta sem consultar a área responsável, ainda que já saiba do posicionamento da empresa em relação à questão, pois é uma forma de participar os gestores sobre as principais insatisfações apresentadas pelos clientes e os respectivos volumes referentes aos processos pelos quais são responsáveis (KALIL, 2013, s.p.). 
A atuação preventiva, por sua vez, diz respeito às ações da ouvidoria que envolvem a sistematização das manifestações, "visando identificar as causas dos principais problemas e propor soluções, minimizando, dessa forma, o número de reclamações" (KALIL, 2013, s.p.). Kalil explica ser a atuação preventiva uma forma de aprimorar serviços, processos, políticas, normas e procedimentos da organização, uma vez que a gestão das manifestações e reclamações possibilita um maior conhecimento dos pontos falhos da organização, a partir do ponto de vista do usuário.

Logo, o ouvidor, junto com sua equipe, colaborando para os processos de transformação da empresa, deve ser um agente de mudanças e, de acordo com as reclamações postuladas pelos clientes, prover grandes alterações a ponto de suprir as deficiências organizacionais nas questões relacionadas aos clientes, cobrando soluções e acompanhando a implementação (KALIL, 2013, s.p.).

Com base nas atividades e abordagens apresentadas, três dimensões principais foram identificadas como pertencentes às ouvidorias públicas, a saber: a funcional, a gerencial e a cidadã.

\section{Dimensão funcional}

A dimensão funcional trata da funcionalidade ou modus operandi de uma ouvidoria. Etimologicamente, funcional se origina do termo "função", do latim functionem, que designa performance, execução, um trabalho específico de alguém (ONLINE ETYMOLOgY Dictionary, 2016).

Apesar de não haver uma padronização a respeito, normalmente as ouvidorias são estabelecidas mediante regimento interno. De acordo com a Pesquisa Coleta OGU $2014,44 \%$ das ouvidorias pesquisadas são estabelecidas mediante regimento interno, $10 \%$ por instrução normativa; $9 \%$ por decreto; $6 \%$ por lei e $31 \%$ por outras formas. É nos documentos constitutivos que estão estabelecidas as funções atribuídas às ouvidorias.

Apesar de contemplar outras funções além de receber, examinar, encaminhar, responder e acompanhar manifestações, essas atividades normalmente são as primeiras indicadas, talvez por serem as mais facilmente identificáveis na rotina de trabalho das ouvidorias. O decreto no 69399/2014, que dispõe sobre as atividades das ouvidorias em São Paulo, indica 16 atribuições da ouvidoria, sendo as primeiras vinculadas às atividades de receber, analisar e responder as manifestações dos cidadãos (SÃo PAULO, 2014). 
As atividades da dimensão funcional são associáveis à atuação reativa da ouvidoria, uma vez que compreendem aquelas comumente realizadas a partir da manifestação do cidadão.

\section{Dimensão gerencial}

Um dos aspectos ressaltados pela OGU (2012), ao tratar da funcionalidade das ouvidorias públicas, é a possibilidade de contribuir para a melhoria da prestação dos serviços públicos. Isso porque a ouvidoria identifica os pontos a serem aprimorados, a partir da manifestação do cidadão, contribuindo para a melhoria dos procedimentos e dos processos administrativos.

A edição 42 de Textos para discussão da Enap (2001) trouxe como temática as ferramentas para o alcance da satisfação do cidadão, citando entre elas os sistemas de ouvidoria. Dentre as funcionalidades comumente conhecidas, como receber, analisar, responder e encaminhar as manifestações, o documento enfatiza o caráter gerencial das ouvidorias, como possibilidade de aprimorar a qualidade dos serviços públicos e, por consequência, a satisfação do cidadão-usuário do serviço. O documento aponta a possibilidade de o ouvidor explorar os registros dos atendimentos, inserindo-os em sistemas de informações sobre a qualidade do serviço público.

$\mathrm{O}$ adequado tratamento dessas informações pode permitir que aflorem aspectos da realidade antes desconhecidos, com a identificação de padrões de comportamento dos usuários-cidadãos dos serviços públicos, a descoberta de relações entre diferentes fenômenos e o entendimento de diferentes características dos processos de avaliação dos serviços públicos pelos usuários (Escola Nacional de Administração Pública, 2001, p.18).

A perspectiva gerencial é coerente com a abordagem de atuação preventiva exposta por Kalil (2013), uma vez que as ações gerenciais decorrentes da análise das reclamações permitem ao órgão público a melhoria da qualidade do serviço.

A lógica da eficiência operacional e da melhoria da qualidade do serviço, muito presentes no meio empresarial, difundiu-se no setor público por meio da Nova Gestão Pública (New Public Management) a partir de meados da década de 1980, portanto, concomitante à própria expansão das ouvidorias públicas. Para Denhardt e Denhardt (2003), o gestor público, quando na perspectiva da Nova Gestão Pública, lidera o aparato estatal buscando maior produtividade e eficiência. Para tanto, faz uso de ferramentas gerenciais advindas do setor privado e importa filosofias de gestão, como tratar o cidadão como cliente. Nesse sentido, a ouvidoria pode ser vista como ferramenta gerencial aplicada ao setor público, visando à melhoria da 
qualidade do serviço público. O risco apontado por Denhardt e Denhardt (2003) com a adoção da abordagem gerencialista consiste na importação das ferramentas gerenciais pautada em valores econômicos e gerenciais, em vez de valores centrados no cidadão e na construção da cidadania. Nesse sentido, a dimensão cidadã da ouvidoria pública mostra-se especialmente relevante, como se observa a seguir.

\section{Dimensão cidadã}

A participação cidadã e o controle social são questões fundamentais ao estabelecimento do Estado Democrático de Direito, garantidos na Constituição Federal de 1988 (CF). Em especial, no artigo 370 da CF, conforme apresentado inicialmente. A possiblidade de reclamação, bem como de acompanhamento da atividade pública mediante o acesso às informações e questionamento destas, quando se mostram irregulares, caracterizam o "controle social". Raichelis (2005) define o termo como

(...) acesso aos processos que informam as decisões da sociedade política. Permite participação da sociedade civil organizada na formulação e na revisão das regras que conduzem as negociações e a arbitragem sobre os interesses em jogo, além da fiscalização daquelas decisões, segundo critérios pactuados (RAICHELIS, 2005, p.43).

No contexto das ouvidorias, o cidadão não tem o poder de estabelecer penalidades jurídicas sobre os agentes da administração pública, conforme esclarece Siraque (2005). Entretanto, pode manifestar-se junto aos órgãos que exercem o papel de controle e dotados de atribuições jurídicas para aplicar penalidades, como exemplo, os ministérios públicos e tribunais de contas. É nesse âmbito que se encontram as ouvidorias públicas, igualmente caracterizadas como órgãos que exercem controle, podendo ser internas ou externas a uma instituição pública (SIRAQUE, 2005).

Assim, dada as funcionalidades apresentadas, a ouvidoria pública é vislumbrada como meio para participação cidadã e controle social, como se observa na afirmação de Antunes (2010, p.147): “a ouvidoria pública é considerada um dos instrumentos de participação cidadã e de possibilidade do controle social, de forma direta, na Administração Pública, na medida em que possibilita à sociedade expressar as suas necessidades".

O olhar da administração pública ao cidadão como um ser político, que pode e deve manifestar sua opinião para construir um Estado mais justo e igualitário e, concomitantemente, desenvolver seu potencial reflexivo, fundamenta o Novo Serviço Público ou New Public Service (Denhardi; Denhardt, 2003). Neste, os instrumentos de participação popular, espaços de diálogo e coprodução do bem 
público são valorizados, uma vez que facilitam o desenvolvimento da própria cidadania. Sob tal aspecto, a dimensão cidadã da ouvidoria pública constitui-se como uma das mais importantes à sociedade.

\section{Procedimentos metodológicos}

O presente estudo foi desenvolvido com o intuito de verificar a existência das dimensões funcional, gerencial e cidadã na atuação das ouvidorias públicas, observando como são aplicadas e percebidas pelos ouvidores. Por ser tema recente e de conteúdo ainda não sistematizado (SANTOS et al., 2015), configura-se como estudo exploratório. Fez-se uso de abordagem predominantemente quantitativa, com levantamento de dados mediante pesquisa survey submetida, via formulário online, a 283 ouvidores do Poder Executivo, no Estado de Santa Catarina. Em Santa Catarina, o Poder Executivo apresenta um sistema de ouvidorias específico, instituído pelo Decreto no 1027, de 21 de janeiro de 2008. O sistema de ouvidorias é formado pelas chamadas ouvidorias setoriais e seccionais, estas vinculadas à Ouvidoria Geral do Estado (OGE/SC), a qual responde à Secretaria de Administração do Estado (SEA/SC).

São ouvidorias setoriais aquelas vinculadas ao âmbito maior do órgão público; e as ouvidorias seccionais aquelas existentes em centros ou departamentos específicos. Esse conglomerado é composto por 283 ouvidorias, entre setoriais, seccionais e a OGE/SC - todas com um ouvidor, e algumas apresentam também equipe de suporte.

Importante destacar que a informação oriunda das manifestações dos cidadãos, bem como seu gerenciamento e controle, é dada pelo Sistema Integrado de Ouvidorias (OUV), ferramenta tecnológica (software) utilizada para "estruturar, organizar e operacionalizar os processos administrativos, tendo como função facilitar o acesso às informações, tornando-as transparentes e garantindo maior agilidade e acesso à prestação de atendimento ao cidadão" (SANTA CATARINA, 2008). A estrutura organizacional e o sistema de informação disponível colocam o Estado entre as ouvidorias públicas de destaque nacional, segundo o Ouvidor Geral do Estado de Santa Catarina.

A operacionalização da pesquisa deu-se em quatro fases: a. levantamento bibliográfico e categorização das dimensões de análise; b. elaboração e validação do instrumento de coleta de dados, incluindo as dimensões de análise; c. coleta de dados; e d. análise dos dados. 
a) Levantamento bibliográfico e categorização das dimensões de análise

O levantamento bibliográfico buscou identificar as funcionalidades atribuídas à ouvidoria. Um dos principais documentos de consulta, que permitiu a categorização das dimensões apresentadas neste estudo, foi a cartilha desenvolvida pela OGU (2012), denominada Orientações para implantação de uma unidade de ouvidoria: rumo ao sistema participativo. A análise das competências indicadas na cartilha resultou na categorização de três dimensões prévias, quais sejam: a funcional, a gerencial e a cidadã.

O aprofundamento na literatura auxiliou o processo, permitindo a confirmação das dimensões no campo teórico. Cabe destacar que a literatura sobre ouvidoria é recente no Brasil e a produção acadêmica na área, incipiente.

Santos et al. (2015) identificaram os objetivos dos artigos científicos produzidos na área, no período entre 2002 e 2013. A produção acadêmica engloba, em sua maioria, pesquisas que analisam as ouvidorias sob a perspectiva da participação cidadã e dos mecanismos de controle, corroborando a dimensão cidadã identificada no estudo. Este é o enfoque dado por Siraque (2005), quando apresenta o papel das ouvidorias.

Além disso, a análise do histórico da ouvidoria no mundo e sua trajetória no Brasil contribuiu para a confirmação das dimensões funcional e gerencial. As obras de Reif (2004) e Howard (2010) esclarecem a funcionalidade da ouvidoria, enquanto a Enap (2001) auxilia na confirmação da dimensão gerencial.

\section{b) Elaboração e validação do instrumento de coleta de dados}

O instrumento de coleta de dados foi desenvolvido com o propósito de identificar o perfil dos ouvidores, levantar informações sobre a estrutura e funcionamento da ouvidoria, bem como observar a ocorrência das dimensões funcional, gerencial e cidadã na rotina dos ouvidores.

Para analisar as dimensões, foram identificadas atribuições específicas, cuja frequência de realização os ouvidores deveriam informar, com as possibilidades de resposta "Sempre"; "Frequentemente"; "Às vezes"; "Raramente"; "Nunca/Não é atribuição desta ouvidoria"; e "Não sei responder". As atividades foram identificadas com base nas competências descritas na cartilha desenvolvida pela OGU (2012). Posteriormente, foram submetidas à análise do Ouvidor Geral e do administrador responsável pela OGE/SC. Após análise, exclusão/inclusão e alteração textual de algumas atividades, o instrumento de coleta contemplou as seguintes atribuições: 
d) Análise dos dados

Os dados de natureza quantitativa foram analisados com auxílio do software SPSS v.23, especialmente para elaboração de frequências, cálculo de médias e desvio padrão. Os dados referentes às dimensões da ouvidoria foram submetidos à análise fatorial exploratória, mediante uso do Software R (R CORE TEAM, 2015).

A análise fatorial exploratória procura identificar a interdependência de múltiplas variáveis e agrupá-las em relação a um fator comum. Assim, determina em seus procedimentos as variáveis que "caminham juntas" em relação às dimensões latentes. Tais dimensões - normalmente caracterizadas como os constructos teóricos do estudo - são denominadas "fatores" na análise fatorial (FIGUEIREDo FILHO; SILVA JUNIOR, 2010). No presente artigo, as variáveis são representadas pelas 11 atribuições das ouvidorias públicas; já as dimensões latentes (fatores) são as três relacionadas ao papel da ouvidoria pública, quais sejam: dimensão funcional, gerencial e cidadã.

\section{Apresentação dos resultados}

Os resultados foram categorizados em perfil dos ouvidores, estrutura das ouvidorias e atribuições das ouvidorias. Num segundo momento, são apresentados os resultados da análise fatorial exploratória em relação às dimensões funcional, gerencial e cidadã, identificadas em fase anterior como próprias da ouvidoria.

\section{Perfil dos ouvidores}

O perfil dos ouvidores foi levantado a partir do tempo de atuação no setor público e como ouvidor, escolaridade e área de formação. A Tabela 1, a seguir, apresenta o perfil dos respondentes em relação às duas primeiras variáveis.

Tabela 1 - Tempo no serviço público, tempo como ouvidor

\begin{tabular}{cccccc}
\hline $\begin{array}{c}\text { Tempo no serviço } \\
\text { público }\end{array}$ & No & $\%$ & $\begin{array}{c}\text { Tempo como } \\
\text { ouvidor }\end{array}$ & № & $\%$ \\
\hline de 01 a 05 anos & 30 & $19,2 \%$ & menos de 1 ano & 51 & $32,7 \%$ \\
\hline de 6 a 10 anos & 32 & $20,5 \%$ & de 1 a 2 anos & 47 & $30,1 \%$ \\
\hline de 11 a 15 anos & 14 & $9,0 \%$ & de 3 a 4 anos & 18 & $11,5 \%$ \\
\hline de 16 a 20 anos & 16 & $10,3 \%$ & de 4 a 5 anos & 12 & $7,7 \%$ \\
\hline mais de 15 anos & 58 & $37,2 \%$ & mais de 5 anos & 28 & $17,9 \%$ \\
\hline Total & $\mathbf{1 5 6}$ & $\mathbf{1 0 0 , 0 \%}$ & Total & $\mathbf{1 5 6}$ & $\mathbf{1 0 0 , 0 \%}$ \\
\hline
\end{tabular}

Fonte: Dados primários, 2016. 
Em relação ao tempo de atuação no setor público, 88 respondentes $(56,5 \%)$ estão vinculados há mais de 11 anos. Especificamente com relação ao tempo de atuação de ouvidor no órgão, o estudo verificou que $52,8 \%$ dos ouvidores desenvolvem esta atividade há menos de dois anos, indicando tratar-se de uma função recente, se comparada ao tempo de atuação na área pública.

\section{Tabela 2 - Escolaridade dos ouvidores}

\begin{tabular}{lcc}
\hline Escolaridade & № & $\mathbf{\%}$ \\
\hline Ensino fundamental & 2 & $1,3 \%$ \\
\hline Ensino médio & 7 & $4,5 \%$ \\
\hline Ensino superior & 41 & $26,3 \%$ \\
\hline Pós-graduação & 106 & $67,9 \%$ \\
\hline Total geral & $\mathbf{1 5 6}$ & $\mathbf{1 0 0 , 0 \%}$
\end{tabular}

Fonte: Dados primários, 2016.

No tocante à escolaridade, a "pós-graduação" foi indicada por 106 ouvidores $(68,4 \%)$, e o "ensino superior" por $26,5 \%$ dos ouvidores pesquisados. Em relação à área de formação, a maior incidência é dada pela área do Direito (29,5\%), seguida pela menção a "outras áreas de conhecimento" totalizando 35,3\%. São graduados em Administração 30 ouvidores, o que representa 19,2\% dos respondentes.

Importante ressaltar que a escolha do servidor para assumir a função de ouvidor não inclui obrigatoriedade de formação em uma área de conhecimento específica. Ainda, segundo o Decreto no 1.027/2008, a escolha do ouvidor ocorre pelo dirigente dos órgãos e entidades da administração direta e indireta, o qual será um servidor público, "sem prejuízo de suas atribuições habituais" (SANTA CATARINA, 2008). Tratase de uma forma distinta, porém mais próxima ao "modelo clássico", descrito por Reif (2004).

\section{Estrutura das ouvidorias}

As ouvidorias do Poder Executivo em Santa Catarina estão estruturadas de acordo com o sistema administrativo da ouvidoria, composto pela Secretaria de Administração do Estado de SC, Ouvidoria Geral do Estado de SC, ouvidorias setoriais e ouvidorias seccionais, cuja relação hierárquica é expressa na Figura 3. 
Figura 3 - Estrutura hierárquica do sistema administrativo de ouvidoria

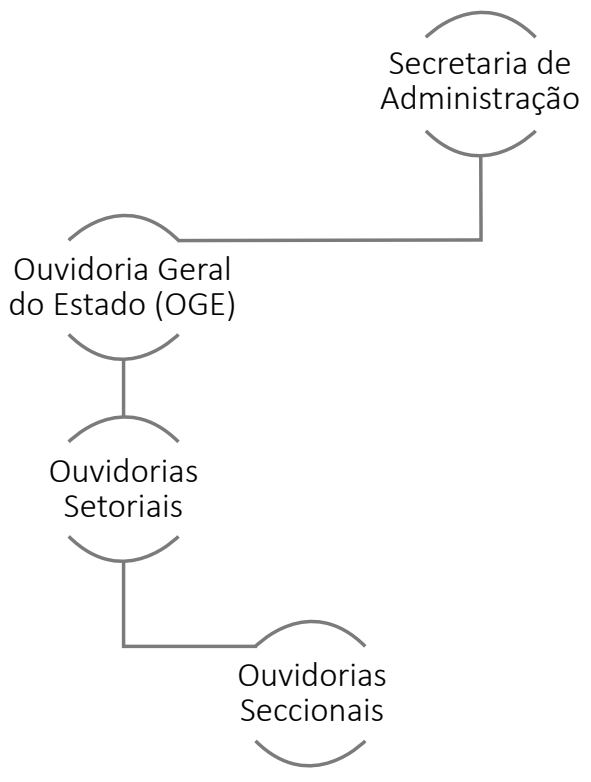

Fonte: adaptado de Santa Catarina (2008).

A divisão entre "setorial" e "seccional" foi criada dada a complexidade da estrutura do governo e para permitir a existência da ouvidoria em diversas localidades. Como exemplo, pode-se citar a Universidade do Estado de Santa Catarina (Udesc), que conta com uma ouvidoria setorial, vinculada à Reitoria, e ouvidorias seccionais, em cada um dos centros de ensino.

Para analisar a estrutura da ouvidora, foram questionados o tempo de funcionamento e o número de pessoas que compõem a equipe. Em relação ao tempo de funcionamento, 43,6\% das ouvidorias participantes da pesquisa estão em funcionamento há mais de 5 anos; as criadas no espaço inferior a um ano perfazem $9 \%$.

São estruturas enxutas, formadas pelo ouvidor somente, ou com suporte de até mais duas pessoas ( $88,6 \%$ dos respondentes). Estrutura com três ou mais funcionários de suporte foram indicadas por $11,4 \%$ dos respondentes.

\section{Atribuições das ouvidorias}

As atribuições das ouvidorias foram identificadas e categorizadas conforme expresso na Figura 2 - Dimensões de análise da ouvidoria x atribuições. As médias e desvio padrão obtidos pela análise dos dados são apresentadas na Tabela 3, sendo que os valores próximos a 5,0 indicam elevada frequência de realização e valores próximos a 1,0 indicam baixa frequência de realização. 
Tabela 3 - Atribuições das ouvidorias

\begin{tabular}{|c|c|c|c|}
\hline Atribuições & $\mathrm{N}$ & Média & $\begin{array}{l}\text { Desvio } \\
\text { Padrão }\end{array}$ \\
\hline 1. Receber as manifestações dos cidadãos. & 156 & 4,006 & 1,2365 \\
\hline $\begin{array}{l}\text { 2. Encaminhar as manifestações dos cidadãos aos } \\
\text { setores internos competentes. }\end{array}$ & 156 & 4,276 & 1,0569 \\
\hline $\begin{array}{l}\text { 3. Cobrar respostas dos encaminhamentos feitos } \\
\text { aos setores competentes. }\end{array}$ & 156 & 4,205 & 1,1624 \\
\hline $\begin{array}{l}\text { 4. Dar respostas aos cidadãos sobre suas } \\
\text { manifestações. }\end{array}$ & 156 & 4,083 & 1,3486 \\
\hline $\begin{array}{l}\text { 5. Encaminhar as manifestações dos cidadãos à } \\
\text { Ouvidoria Geral do Estado. }\end{array}$ & 156 & 3,660 & 1,6363 \\
\hline $\begin{array}{l}\text { 6. Divulgar a existência e atribuições da ouvidoria } \\
\text { para a sociedade utilizando os meios disponíveis } \\
\text { de comunicação. }\end{array}$ & 156 & 2,494 & 1,4789 \\
\hline $\begin{array}{l}\text { 7. Elaborar relatórios sobre as demandas dos } \\
\text { cidadãos. }\end{array}$ & 156 & 2,474 & 1,6122 \\
\hline $\begin{array}{l}\text { 8. Divulgar relatórios com indicadores das } \\
\text { demandas para a comunidade utilizando os } \\
\text { meios disponíveis de comunicação. }\end{array}$ & 156 & 1,872 & 1,3712 \\
\hline $\begin{array}{l}\text { 9. Divulgar relatórios com indicadores das } \\
\text { demandas para os gestores internos do órgão. }\end{array}$ & 156 & 2,282 & 1,6216 \\
\hline $\begin{array}{l}\text { 10. Estimular que o cidadão manifeste suas } \\
\text { demandas pela ouvidoria utilizando os canais } \\
\text { específicos de comunicação (website da } \\
\text { instituição, telefone, e-mail). }\end{array}$ & 156 & 2,808 & 1,6348 \\
\hline $\begin{array}{l}\text { 11. Estimular que o cidadão cobre serviços } \\
\text { públicos de maior qualidade. }\end{array}$ & 156 & 2,853 & 1,6177 \\
\hline
\end{tabular}

Fonte: Dados primários, 2016.

As médias mostram-se maiores nas atribuições "receber manifestações dos cidadãos", "encaminhá-las aos setores internos competentes", "cobrar respostas dos encaminhamentos aos setores competentes", "dar resposta aos cidadãos sobre suas manifestações", indicando que tais atribuições são realizadas com alta frequência. Também é perceptível desvios-padrão em menor grau nesse grupo, indicando baixa variação de respostas. Na sequência, a média mais elevada é dada pela atribuição "encaminhar as manifestações dos cidadãos à OGE", porém com maior desvio padrão, indicando pouca uniformidade nas respostas. São atribuições pertencentes à dimensão funcional, conforme categorização prévia, exceto a atribuição 5 (dimensão gerencial). 
As atribuições "divulgar a existência e atribuições da ouvidoria para a sociedade utilizando os meios disponíveis de comunicação", "elaborar relatórios sobre as demandas dos cidadãos" e "divulgar relatórios com indicadores das demandas para a comunidade utilizando os meios disponíveis de comunicação" obtiveram as menores médias, o que revela uma baixa frequência de realização. Os desviospadrão elevados (exceto atribuição 8), caracterizando pouca homogeneidade das respostas. Conforme categorização prévia, tais atividades enquadram-se nas dimensões gerencial e cidadã.

De acordo com o Ouvidor da OGE e com o servidor administrador responsável, a divulgação da existência da ouvidoria ocorre no website da instituição, sendo raras as iniciativas de divulgação com uso de cartaz no próprio órgão público ou por outros meios de comunicação. Não há registro de campanha institucional informando a existência e funcionalidade da ouvidoria, configurando-se como um desafio na área. Da mesma forma, a divulgação de relatórios sobre o atendimento às demandas é incipiente e, quando ocorre, é feito no website da instituição ou fornecido mediante solicitação do cidadão. Pontua-se nesta pesquisa que a divulgação da existência da ouvidoria é necessária para que o cidadão reconheça a existência deste órgão, bem como sua funcionalidade, e então possa realizar sua manifestação.

Duarte (2007, p.112) comenta sobre o papel da comunicação na construção da cidadania. A autora aponta desafios à realidade brasileira, ainda incapaz de usar toda a amplitude disponível dos diferentes meios de comunicação. Relata, também, que a informação divulgada nem sempre é aquela que o cidadão necessita - "é, antes de tudo, aquilo que interessa ao órgão ou à empresa divulgar". A autora igualmente critica a atitude passiva frente à divulgação das informações na internet: "Fazemos a nossa parte - os dados estão na internet!' - se o cidadão tem acesso a eles ou não é insignificante, pois o compromisso da transparência já teria sido assegurado pela publicação dos conteúdos em sítios oficiais".

A divulgação restrita da ouvidoria e dos resultados sobre o tratamento dado às demandas, reflete-se nas atribuições "estimular que o cidadão manifeste suas demandas pela ouvidoria, utilizando canais específicos de comunicação" e "estimular que o cidadão cobre serviços públicos de maior qualidade", visto que as médias são inferiores a 3,00. Entretanto, os índices de desvio-padrão elevados mostram alta variação de respostas, indicando que, para alguns, tal estímulo é presente. Tais atribuições foram previamente categorizadas como pertencentes à dimensão cidadã, sendo que os dados apresentados corroboram a situação desafiadora na comunicação como estímulo à cidadania, exposta por Duarte (2007). 


\section{Análise fatorial exploratória das dimensões funcional, gerencial e cidadã}

Além de caracterizar as ouvidorias na percepção dos ouvidores, o estudo buscou verificar a existência das dimensões identificadas mediante aplicação de análise fatorial exploratória. Os dados foram submetidos ao software $\mathrm{R}$, levando em consideração as onze atribuições apresentadas na Figura 2 - Dimensões de análise da ouvidoria $x$ atribuições.

A estimação por meio da análise fatorial de informação plena (full information), com base na matriz de correlação policórica, verificou a existência de duas dimensões - e não três, como proposto previamente. A indicação de tais dimensões pode ser visualizada no screen plot (Figura 4) e as cargas fatoriais na Tabela 4 a seguir.

\section{Figura 4 - Scree plot}

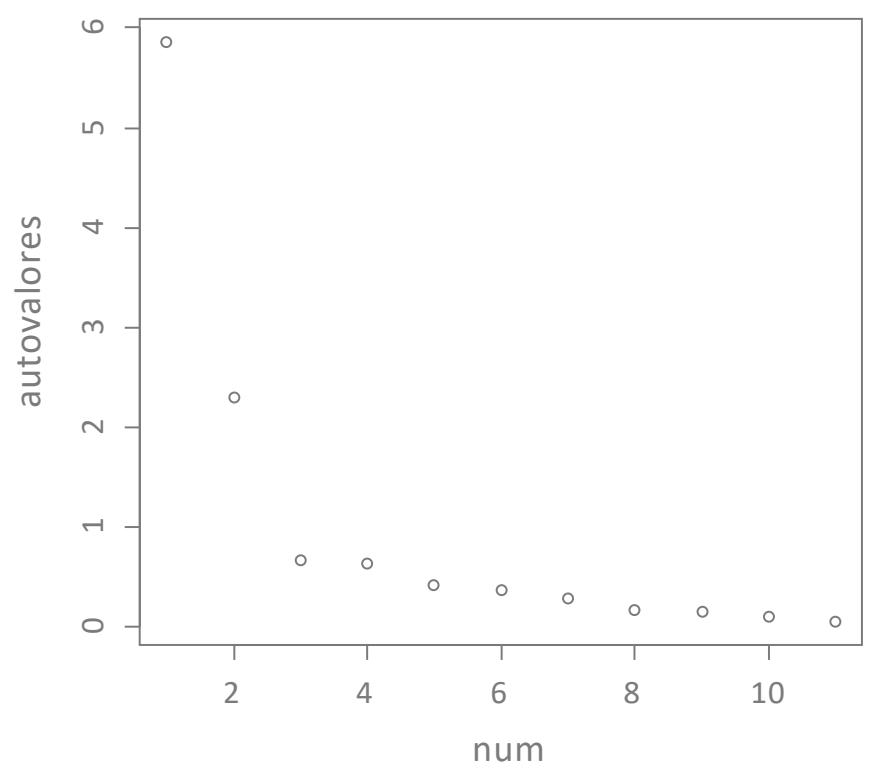

Fonte: Dados primários, 2016. 
Tabela 4 - Matriz de correlação

$$
\text { Item }
$$

A1. Receber as manifestações dos cidadãos

A2. Encaminhar as manifestações

dos cidadãos aos setores internos competentes.

\section{A3. Cobrar respostas dos} encaminhamentos feitos aos setores competentes.
F1

0.100

0.707

$-0.090$

0.959

0.866
0.561

Comunalidade

A4. Dar respostas aos cidadãos sobre suas manifestações.

$\begin{array}{lll}0.031 & \mathbf{0 . 8 5 2} & 0.746\end{array}$

B1. Encaminhar as manifestações dos cidadãos à Ouvidoria Geral do Estado.

$\begin{array}{lll}0.080 & \mathbf{0 . 7 7 9} & 0.657\end{array}$

B2. Elaborar relatórios sobre as demandas dos cidadãos.

$\begin{array}{lll}0.056 & \mathbf{0 . 7 2 3} & 0.555\end{array}$

B3. Divulgar relatórios com indicadores das demandas para os gestores internos do órgão.

$\begin{array}{lll}\mathbf{0 . 7 6 8} & 0.052 & 0.621\end{array}$

C1. Divulgar a existência e atribuições da ouvidoria para a sociedade utilizando os meios disponíveis de comunicação.

$\begin{array}{lll}\mathbf{0 . 9 1 5} & -0.004 & 0.834\end{array}$

C2. Divulgar relatórios com indicadores das demandas para a comunidade utilizando os meios disponíveis de $\begin{array}{lll}0.937 & 0.037 & 0.905\end{array}$ comunicação.

C3. Estimular que o cidadão manifeste suas demandas pela ouvidoria, utilizando os canais específicos de comunicação.

$\mathbf{0 . 9 8 4}-0.225 \quad 0.861$

C4. Estimular que o cidadão cobre serviços públicos de maior qualidade.

$\begin{array}{lll}\mathbf{0 . 7 5 9} & 0.270 \quad 0.795\end{array}$

Fonte: Dados primários, 2016.

A análise permite verificar que os itens $A 1, A 2, A 3, A 4$ e $B 1$ são itens predominante do fator F2, e os itens B2, B3, C1, C2, C3 e C4 do fator F1, caracterizando as duas dimensões mencionadas. Ou seja, a partir de duas dimensões principais foram categorizadas as atribuições das ouvidorias. Cabe destacar que a rotação utilizada foi a oblimin, a qual considerou uma correlação entre as dimensões de 0.357. 
A Figura 5 apresenta quais atribuições foram alocadas em cada uma das novas dimensões "F1" e "F2".

\section{Figura 5 - dimensões $x$ atribuições da ouvidoria}

\begin{tabular}{|c|c|c|}
\hline Dimensão & $\begin{array}{c}\text { Nova } \\
\text { dimensão }\end{array}$ & Atribuição \\
\hline \multirow{4}{*}{$\begin{array}{l}\text { Dimensão } \\
\text { funcional }\end{array}$} & \multirow{5}{*}{$\begin{array}{l}\text { F1 } \\
\text { mensão } \\
\text { ncional }\end{array}$} & Receber as manifestações dos cidadãos. \\
\hline & & $\begin{array}{l}\text { Encaminhar as manifestações dos cidadãos aos setores } \\
\text { internos competentes. }\end{array}$ \\
\hline & & $\begin{array}{l}\text { Cobrar respostas dos encaminhamentos feitos aos } \\
\text { setores competentes. }\end{array}$ \\
\hline & & Dar respostas aos cidadãos sobre suas manifestações. \\
\hline \multirow{3}{*}{$\begin{array}{l}\text { Dimensão } \\
\text { gerencial }\end{array}$} & & $\begin{array}{l}\text { Encaminhar as manifestações dos cidadãos à Ouvidoria } \\
\text { Geral do Estado. }\end{array}$ \\
\hline & \multirow{6}{*}{$\begin{array}{c}\text { F2 } \\
\text { Dimensão } \\
\text { gerencial- } \\
\text { cidadã }\end{array}$} & Elaborar relatórios sobre as demandas dos cidadãos. \\
\hline & & $\begin{array}{l}\text { Divulgar relatórios com indicadores das demandas para } \\
\text { os gestores internos do órgão. }\end{array}$ \\
\hline \multirow{4}{*}{$\begin{array}{l}\text { Dimensão } \\
\text { cidadã }\end{array}$} & & $\begin{array}{l}\text { Divulgar a existência e atribuições da ouvidoria } \\
\text { para a sociedade utilizando os meios disponíveis de } \\
\text { comunicação. }\end{array}$ \\
\hline & & $\begin{array}{l}\text { Divulgar relatórios com indicadores das demandas } \\
\text { para a comunidade utilizando os meios disponíveis de } \\
\text { comunicação. }\end{array}$ \\
\hline & & $\begin{array}{l}\text { Estimular que o cidadão manifeste suas demandas } \\
\text { pela ouvidoria, utilizando os canais específicos } \\
\text { de comunicação (website da instituição, telefone, } \\
\text { e-mail). }\end{array}$ \\
\hline & & $\begin{array}{l}\text { Estimular que o cidadão cobre serviços públicos de } \\
\text { maior qualidade. }\end{array}$ \\
\hline
\end{tabular}

Fonte: Dados primários, 2016.

Considerando os dados obtidos, propõem-se duas novas dimensões às ouvidorias públicas: a dimensão funcional e a dimensão gerencial-cidadã, sendo a dimensão gerencial absorvida, predominantemente, pela dimensão cidadã. As dimensões apresentadas refletem o estágio de desenvolvimento das ouvidorias analisadas, cujas atividades mais frequentes centram-se na dimensão funcional. A dimensão gerencial-cidadã, embora existente, ocorre em menor frequência e carece de mais cuidados para que a ouvidoria possa, de fato, realizar plenamente seu propósito. 


\section{Considerações finais}

Qual o papel de uma ouvidoria pública? De que forma tal papel é posto em prática?

A gênese da ouvidoria no Brasil, especialmente no período de redemocratização, parte de um desejo de empoderamento da população brasileira, banhada em espírito democrático e esperançosa de uma participação cidadã que estimule o controle social.

A participação cidadã e o controle social são formas de fortalecer a conexão entre cidadãos e seus governos. Denhardt (2012, p. 255) enfatiza que o cidadão consegue desenvolver uma "existência de virtude" apenas quando atua "tendo por referência o interesse público", contribuindo para a comunidade.

Outrossim, a ouvidoria surge com a incumbência de estabelecer tal conexão, construindo uma ponte entre o governo e o cidadão, permitindo-Ihe e estimulando-o a manifestar sua reclamação, elogio, sugestão ou solicitação de informações. É notório que as manifestações podem surgir de uma intenção individual, mas, na medida em que permitem a melhoria do serviço público, seus efeitos podem alcançar a contribuição à comunidade.

É dessa perspectiva que a presente pesquisa toma corpo: de um entendimento sobre a importância da ouvidoria nesse papel de conexão e da curiosidade em saber quais são e como são cumpridos os demais papéis de uma ouvidoria pública.

Para tanto, um levantamento de dados, mediante uso de pesquisa survey, foi empreendido, resultando na participação de 156 ouvidores de órgãos vinculados ao Poder Executivo, no Estado de Santa Catarina. Além da caracterização dos ouvidores e ouvidorias pesquisadas, a pesquisa revelou que as atividades realizadas com maior frequência são aquelas pertencentes à dimensão funcional, quais sejam "receber manifestações dos cidadãos", "encaminhá-las aos setores internos competentes", "cobrar respostas dos encaminhamentos aos setores competentes", "dar resposta aos cidadãos sobre suas manifestações", além de "encaminhar as manifestações dos cidadãos à OGE", esta categorizada como dimensão gerencial.

Assim, quando os cidadãos fazem suas manifestações, estas são recebidas, analisadas pelos ouvidores e setores competentes, os quais devem prover uma resposta ao cidadão. As informações são repassadas à OGE, garantindo o controle dos dados. A dimensão funcional e suas atribuições foram identificadas na análise fatorial exploratória, apresentando índices de correlação superiores a 0,7.

As demais atribuições caracterizaram uma única dimensão - e não duas, como previsto na pesquisa. Igualmente com índices de correlação elevados, a análise indicou a presença de uma dimensão que mescla atribuições cidadã e gerencial. 
O resultado espelha as atividades desenvolvidas com maior e menor frequência pelas ouvidorias pesquisadas: enquanto as atribuições da dimensão funcional são realizadas com elevada incidência, aquelas pertencentes à dimensão gerencialcidadã ainda se mostram incipientes, revelando um desafio às ouvidorias do Poder Executivo de Santa Catarina.

Divulgar a existência da ouvidoria, apresentando sua funcionalidade, é uma das formas de estimular o cidadão a cobrar serviços públicos de melhor qualidade. Para além desta, outras formas de estímulo podem ser construídas, visando ao desenvolvimento do senso de cidadania e participação. Entretanto, se o estímulo e a divulgação são ausentes ou fracos, como o cidadão pode manifestar-se, uma vez que ele sequer reconhece a existência ou funcionalidade da ouvidoria pública?

Em estudo desenvolvido por Vázquez et al. (2005), os autores investigaram o nível de conhecimento da população sobre os mecanismos de participação social em saúde, no qual se incluem as ouvidorias de saúde. O levantamento de dados ocorreu em 2000, junto à população da região metropolitana de Recife (Cabo e Camaragibe). Participaram da pesquisa mais de 1500 moradores e os dados revelaram que a ouvidoria de saúde é o mecanismo de participação com menor nível de conhecimento pela população, sendo reconhecido por apenas $4 \%$ dos entrevistados no município de Cabo, e por 6,5\% em Camaragibe. Naturalmente, o intervalo de 16 anos pode não mais representar o quadro atual, mas revela uma preocupação no tocante ao tema.

Cabe destacar a escassez de pesquisas sobre ouvidorias públicas explorando o nível de conhecimento da população sobre tais órgãos. Santos et al. (2015) indicam o estudo de Vázquez et al. (2005) como o único no âmbito acadêmico das produções realizadas no período entre 2002 a 2013 em eventos da Anpad (área de Gestão/ Administração Pública) e periódicos.

Dessa forma, o desenvolvimento da presente pesquisa revela um vasto campo de estudo, relevante à área pública. Pontua-se como possibilidade de estudos futuros a investigação sobre o nível de conhecimento da população em relação às ouvidorias públicas; análise da atuação da ouvidoria nas instâncias federal e municipal, permitindo a comparação entre as diferentes esferas de poder; igualmente, investigar a atuação e configuração das ouvidorias nos âmbitos Judiciário e Legislativo.

Os questionamentos de natureza empírica podem ser analisados à luz de teorias e assuntos diversos, com destaque àqueles que tratam da accountability, participação cidadã, controle social e dos mecanismos de controle. A atuação da ouvidoria pode ser cotejada à perspectiva do Novo Serviço Público (DENHARDT; DenhardT, 2003), New Public Management, e da administração burocrática, 
buscando revelar interfaces com uma ou mais abordagens, de acordo com a prática gerencial e valores compartilhados pelos ouvidores públicos.

Considerando o exposto, este estudo adiciona-se aos demais sobre ouvidoria pública, numa tentativa de compreender tais organizações/setores e contribuir ao campo. Necessário pontuar que os dados aqui apresentados refletem o universo de pesquisa analisado, ou seja, as ouvidorias públicas vinculadas ao Poder Executivo de Santa Catarina, não sendo passíveis de generalização a outras esferas de Poder, unidades da Federação ou instâncias municipais ou federais.

\section{Referências bibliográficas}

ARENDT, H. A condição humana. 10. ed. Rio de Janeiro: Forense Universitária, 2004. ABRUCIO, F. L. O impacto do modelo gerencial na administração pública: um breve estudo sobre a experiência internacional recente. Cadernos Enap, n. 10, 1997. 52 p. Instituto de Pesquisas Econômicas e Aplicadas (IPEA); Controladoria Geral da UNIÃo (CGU). Pesquisa Coleta OGU 2014. Brasília: DF, 2015. Disponível em: http:// www.cgu.gov.br/Publicacoes/ouvidoria/arquivos/coleta-ogu-2014.pdf Acesso em: 12 mar. 2016.

CONTROladoria Geral da União (CGU). Aplicação da Lei de Acesso à Informação a Recursos da CGU. Brasília -DF,2015. Disponível em: http://www.cgu.gov.br/ Publicacoes/ouvidoria/arquivos/aplicacao-da-lei-de-acesso-a-informacao.pdf Acesso em 15-03-2016.

DENhARDT, J. V.; DENhARDT, R. B. The new public service: serving, not steering. New York, NY: M.E.Sharpe, 2003.

DenhardT, R. Teoria da administração pública. São Paulo: Cengage Learning, 2012.

DuARTE, M. Y. M. Comunicação e cidadania. In: DuARTE, J. Comunicação pública: Estado, governo, mercado, sociedade e interesse público. São Paulo: Atlas, 2007.

Escola Nacional de AdMINISTRAÇÃo PúBlicA (ENAP). Experiências internacionais voltadas para a satisfação dos usuários-cidadãos com os serviços públicos. Brasília: Enap, 2001. 65f. (Texto para discussão, 42).

FigueIREDo FILHo, Dalson Brito; Silva JUNIOR, José Alexandre da. Visão além do alcance: uma introdução à análise fatorial. Opinião Pública, Campinas, v. 16, n. 1, p. 160-185, jun. 2010.

FINK, A. The survey handbook. Thousand Oaks: Sage, 1995a. [The survey kit, v.1]

FINK, A. How to sample in surveys. Thousand Oaks: Sage, 1995b. [The survey kit, v.6] HOWARD, C. The organizational ombudsman: origins, roles and operations - a legal guide. Chicago: ABA Publishing, 2010.

KALIL, E. Como implantar ouvidoria e atuar nessa área. São Paulo: Trevisan Editora, 2013. 
LACERDA, A. V. As ouvidorias do Brasil Colônia. Curitiba: Juruá, 2007.

LIMA, Paulo Daniel Barreto. A excelência em gestão pública: a trajetória e a estratégia do Gespública. Rio de Janeiro: QualityMark, 2007.

MoRAES, D. et al. A ouvidoria como um processo democrático: sua história e experiência no Pará. Belém: Secretaria do Estado da Administração (Sead), Governo do Pará, 2010. Disponível em: http://www.sead.pa.gov.br/sites/default/files/ ouvidoriacomoprocessodemocraticohistoriadasouvidorias.pdf .Acesso em: 31 jan. 2017.

NASSUNO,M. et al. Experiências internacionais voltadas para a satisfação dos usuários-cidadãos com os serviços públicos. Brasília: Enap, 2001.

OUVIDORIA GERAL DA UNIÃO (OGU). Orientações para implementação de uma unidade de ouvidoria. 5. ed. Brasília - DF: OGU, 2012. Disponível em: http://www. cgu.gov.br/Publicacoes/ouvidoria/arquivos/ogu-implantacao-unidade-ouvidoria. pdf . Acesso em: 15 fev. 2016.

ONLINE Etymology DictionaRy.Function.2016.Disponível em: http://etymonline. com/index.php?allowed_in_frame=0\&search=function Acesso em: 20 mar. 2016.

Pó, M. V.; AbRUcio, F. L. Desenho e funcionamento dos mecanismos de controle e accountability das agências reguladoras brasileiras: semelhanças e diferenças. Revista de Administração Pública, Rio de Janeiro, vol. 40, n.4, p. 679-698, jul. 2006.

RAICHELIS, Raquel. Esfera pública e conselhos de assistência social: caminhos da construção democrática. 3. ed. São Paulo: Cortez, 2005.

R CORE TEAM. $R$ : a language and environment for statistical computing., Vienna, Austria: R Foundation for Statistical Computing, 2015. Disponível em: http:// www.R-project.org/.

REIF, L. The ombudsman, good governance and the international human rights system. Leiden: Springer Science+Business Media Dordrecht, 2004.

ROMERO, H. H. SANT'ANNA, F. C. C. M. O papel das ouvidorias na comunicação pública do Poder Judiciário. Revista do Serviço Público, v. 65, n. 2, p.185-198 abr./jun. 2014. SANTA CATARINA. Decreto no 1.2017, de 21 de janeiro de 2008. Dispõe sobre a estruturação e administração do Sistema Administrativo da Ouvidoria, no âmbito da administração direta, autárquica e fundacional, e estabelece outras providências. Santa Catarina - SC,2008.Disponívelem: http://server03.pge.sc.gov. br/LegislacaoEstadual/2008/001027-005-0-2008-002.htm - Acesso em: 20 mar. 2016.

SANTOS, A. R. et al. A produção acadêmica sobre ouvidoria pública: um estudo em eventos e periódicos no período de 2002 a 2013. In: ENCONTRO NACIONAL DA AsSociação Nacional de Pesquisa e Pós-GRaduação em AdMINISTRAÇÃo (ANPAD), 39., set. 2015, Belo Horizonte, MG, Brasil. Anais... Belo Horizonte: Anpad, 2015.

SÃo PAULO. Decreto no 60.399, de 29 de abril de 2014. Dispõe sobre a atividade das Ouvidorias instituídas pela Lei no 10.294, de 20 de abril de 1999. São Paulo - SP, 2014. 
SIRAQUe, V. Controle social da função administrativa do Estado: possibilidades e limites na Constituição de 1988. São Paulo: Saraiva, 2005.

VÁzQUEZ, M. L. et al. Nível de informação da população e utilização dos mecanismos institucionais de participação social em saúde em dois municípios do Nordeste do Brasil. Ciência \& Saúde Coletiva, Rio de Janeiro, RJ, Vol.10(supl), p.141-155, 2005.

\title{
Agradecimentos:
}

O presente trabalho tem apoio da Fundação de Amparo à Pesquisa de Santa Catarina (FAPESC) e da Universidade do Estado de Santa Catarina (UDESC), mediante projeto aprovado no Edital 04/2018 da FAPESC.

\begin{abstract}
Aline Regina Santos
Universidade do Estado de Santa Catarina (UDESC). Doutora em Engenharia de Produção pela Universidade Federal de Santa Catarina (UDESC). Professora do Curso de Graduação em Administração Pública e do Programa de Pós-Graduação em Administração do Centro de Ciências da Administração e Socioeconômicas - ESAG/UDESC. aline.santos@udesc.br, http://lattes.cnpq.br/9210124458700096, https://orcid.org/0000-0001-9116-9247

Jane lara Pereira da Costa

Universidade do Estado de Santa Catarina (UDESC). Doutora em Engenharia de Produção pela Universidade Federal de Santa Catarina (UDESC). Professora do Curso de Graduação em Administração de Empresas do Centro de Ciências da Administração e Socioeconômicas - ESAG/UDESC. jane.costa@udesc.br, http://lattes.cnpq. br/5450672714788848
\end{abstract}

\section{Fabrício Burger}

Sem vínculo com IES. Mestre em Engenharia e Gestão do Conhecimento pela Universidade Federal de Santa Catarina (UDESC). Pós-Graduando em Gestão de Projetos pela Universidade de São Paulo (USP). Bacharel em Administração de Empresas pela Universidade do Estado de Santa Catarina (UDESC). fabriciohere@gmail.com, http://lattes.cnpq.br/7726992788377408

\section{Rafael Tezza}

Universidade do Estado de Santa Catariana (UDESC). Doutor em Engenharia de Produção pela Universidade Federal de Santa Catarina (UDESC). Professor dos Programas de Graduação e Pós-Graduação em Administração de Empresas do Centro de Ciências da Administração e Socioeconômicas - ESAG/UDESC. rafael.tezza@udesc.br, http://lattes.cnpq.br/9770620834891213, https://orcid.org/0000-0002-6539-4608 